\title{
Dry Needling and Management of Trigger Points with Low Back Pain: An Evidence to Practice Review
}

\author{
Matthew J. Drescher, DAT, LAT, ATC; Matthew J. Rivera, DAT, LAT, ATC; Lindsey E. Eberman, PhD, LAT, ATC
}

Indiana State University, Terre Haute, IN

\begin{abstract}
Low back pain is a common health concern. The development of myofascial trigger points due to low back pain can cause debilitating pain and loss of functional movement in patients. Dry needling is a minimally invasive procedure that has shown to be useful in the treatment of myofascial trigger points when used with other forms of treatment. However, the literature surrounding dry needling and myofascial trigger points in patients with low back pain is lacking. The guiding systematic review and meta-analysis sought to analyze the effectiveness of dry needling for patients with low back pain. The review utilized eight databases for randomized controlled trials and selected 11 of 784 articles for analysis based on inclusion and exclusion criteria. A 6-subgroup meta-analysis was conducted on these studies, and 6 of the 11 studies were found to have high risk of bias. The included studies used both pain measurements and functional measurements including the visual analogue scale (VAS), Oswestry Disability Index (ODI), and the Roland-Morris Disability Questionnaire (RDQ). The studies did not include objective functional measurements. Overall researchers found a clinically meaningful decrease in outcome scores in the short-term, but there were no significant differences in pain or functional outcomes through long-term follow-up. This seems to correlate with the current literature on dry needling and its inflammatory effects on the body, suggesting that dry needling alone does not provide any long-term effect on myofascial trigger points in patients with low back pain. Dry needling should be combined with other treatments and high-quality rehabilitation to provide longer-lasting results and better treatment outcomes for patients with low back pain.
\end{abstract}

\section{Key Phrases}

Functional testing, manual therapies, patientreported outocmes

\section{Correspondence}

Dr. Matthew Drescher, $567 \mathrm{Nth} 5^{\text {th }} \mathrm{St}$, Terre Haute, IN 47809.

E-mail: mdrescher@sycamores.indstate.edu

Twitter: @Matt_Drescher

\section{Full Citation}

Drescher MJ, Rivera MJ, Eberman LE. Dry Needling and Management of Trigger Points with Low Back Pain: An Evidence to Practice Review. Clin Pract Athl Train. 2021;4(2): 21-25. https://doi.org/10.31622/2021/0004.2.3.

Submitted: October 16, 2020 Accepted: March 11, 2021.

Copyright (C) by Indiana State University All rights reserved. ISSN Online 2577-8188

\section{ORIGINAL REFERENCE}

Liu L, Huang QM, Liu QG, Thitham N, Li LH, Ma YT, Zhao JM. Evidence for dry needling in the management of myofascial trigger points associated with low back pain: a systematic review and meta-analysis. Arch. Phys. Med. Rehabil. 2018, 1;99(1):144-52.

\section{SUMMARY}

\section{CLINICAL PROBLEM AND QUESTION}

Low w back pain (LBP) is a common healthcare concern worldwide for both the patient and the healthcare system itself. This has subsequent burden, both socially and economically, to the patient and the healthcare system. ${ }^{1}$ In many cases, the development of myofascial trigger points (MTrPs) due to chronic LBP can cause debilitating pain and loss of function in patients. MTrPs are defined by Simons et al. as a hyperirritable nodule within a taut band of muscular fibers, and these are typically painful to palpation.2 Dry needling (DN) is a minimally invasive therapy that uses small monofilament needles to produce physiological changes in the patient, most often targeted at muscle tissue. ${ }^{3}$ It is widely accepted that the needle causes microtrauma in the tissue, resulting in a cascade of physiologic events that produce changes in the body. These changes include pain modulation (via gate-control and descending pain control theories), increased blood flow, and reduction in taut band activity in the muscle. ${ }^{4,5}$ Current physiological theory states that taut bands of muscle and MTrPs cause ischemic conditions within the muscle leading to the increase in acetylcholine left in the interstitial tissue. This causes sensitization of peripheral pain receptors, 
and it is hypothesized that long-term peripheral sensitization can cause central nervous system sensitization in the spinal cord leading to chronic pain.6,7

Previous literature suggests that $D N$ treatment improves the outcomes in patients with MTrPs when combined with other treatments. ${ }^{8}$ However, current literature on utilizing $D N$ treatments on MTrPs in patients with LBP is lacking. Further, the quality of evidence is low due to low sample sizes. The guiding systematic review and meta-analysis sought to provide a quantitative analysis on the effectiveness of DN for patients with MTrPs when compared to other treatments individually and in combination with other treatments.

\section{SUMMARY OF LITERATURE}

The guiding review used eight databases and searched for randomized controlled trials that included patients with diagnosed LBP and MTrPs, DN used as a treatment alone, and pain and or functional movement used as an outcome measure. While this review evaluated studies that compared DN to other treatments, these studies must have studied DN alone as well. This review did not include studies that compared different types of dry needling to each other, randomized control trials had no data, full text could not be obtained, or did not define MTrPs by the criteria set by Simons et al. ${ }^{2}$ Two blind reviewers evaluated the validity of studies based on the methodologic quality criteria list. Of the original 784 articles identified by the original search, 11 randomized control trials were selected for analysis. A 6-subgroup meta-analysis was conducted on the selected randomized control trials that evaluated pain outcomes and functional disability outcomes at post-intervention and follow-up. Of the 11 studies included, 6 presented with high risk of bias due to lack of blinding of practitioners and patients, low trial numbers, or low patient recruitment. There is also limited information on objective measurement of functional scores or pain due to lack of integration in the studies reviewed.

\section{SUMMARY OF OUTCOMES}

The outcomes used within the included studies were pain intensity scores either by visual analogue scale (VAS) or an alternate Likert scale, and functional disability with either the Oswestry Disability Index (ODI) or the Roland-Morris Disability Questionnaire (RDQ). One study utilized a custom Likert scale model for pain intensity and functional disability. Both ranged from 0-3, with 0 being no pain or restriction, respectively, and 3 being severe pain or restriction, respectively. ${ }^{9}$ Overall, 10 studies utilized the VAS, 10-19 3 studies utilized the ODI, 16, 17, 19 and 7 studies utilized the RDQ. ${ }^{10-15,} 19$ In the original studies, researchers identified clinically meaningful improvements in the outcome scores in all recorded outcome measures after the use of $\mathrm{DN}$ intervention. However, the differences ranged between studies, where some studies only found moderate changes and others showed large improvements. One study did not assess functional disability, focusing only on VAS scores. ${ }^{18}$

\section{FINDINGS AND CLINICAL IMPLICATIONS}

At post-intervention, DN alone saw significant improvements in pain and functional disability outcomes compared to other treatments. ${ }^{20}$ However, at follow-up evaluation there were no significant differences in pain and functional disability outcomes between the two groups. Only two of the studies compared DN alone with DN used in combination with other treatments. These studies found significant improvements in pain scale scores in the short term for DN used in combination with other treatments when compared to using DN alone. This evidence illustrates the usefulness in DN as a treatment in the short-term improvement of pain and functional disability, which could provide an opportunity for patients to see greater improvements during therapeutic exercise sessions. 
The results from treatment are mostly local physiological responses, similar to an acute laceration in the tissue. While there is no current literature on the healing response to dry needling specifically, it seems to reason that because DN has an acute inflammatory mechanism in the body, in terms of direct tissue disruption, the effects would only last for a short time. Thus, without further treatment such as therapeutic exercise to solidify tissue changes due to this disruption during the subsequent healing phases, the relief gained from dry needling would only be short lived, and this is reflected by the results in both clinical trials and meta-analytical research both physiologically and functionally. 5,21

Interestingly, current literature also shows that DN has been effective in eliciting higher passive peak torque, muscle compliance, and stretch tolerance in target tissues at immediate follow-up and at 15 minutes post-intervention compared to static stretching, and this may account for the improvement in functional disability scales immediately after treatment but not during longterm follow-up. ${ }^{22}$ This seems to be a distinct effect of DN separate from the local tissue disruption and inflammatory response, however other research suggests that DN has the same moderate to long-term effects on peak torque, muscle compliance, and stretch tolerance as static stretching. ${ }^{23}$ Therefore, it seems that the DN response would not continue past the short-term without further stimulation such as follow-up therapeutic exercise. These factors shed light onto the short-term effects seen by studies investigating DN alone. Furthermore, low back pain is often a multifactorial pathology. The multiple mechanisms of treatment that occur from DN may explain why there are beneficial effects for patients with LBP within the short-term window as shown by the guiding review. ${ }^{20}$

A majority of studies in this review had a high risk of bias due to lack of blinding of patients or practitioners. However, it is nearly impossible in

Copyright (C) by Indiana State University All rights reserved. ISSN Online 2577-8188 clinical outcomes research, specifically with manual therapy, to blind study participants to the treatment. In addition, the clinicians must know what treatment they are performing to actually perform the treatment. While single-blind randomized controlled trials could be performed, there is still a necessary unblinding required for this type of research.

\section{CLINICAL BOTTOM LINE}

Dry needling, while useful alone in the short-term to decrease pain and dysfunction, should be combined with other treatments and rehabilitation to provide longer-lasting results and better treatment outcomes in both the short-term and long-term treatment of LBP. While the risk of bias within manual therapy research is high, future research should endeavor to continue with highly rigorous research with focus on the physiological effects of dry needling.

\section{REFERENCES}

1. Dagenais S, Caro J, Haldeman S. A systematic review of low back pain cost of illness studies in the United States and internationally. Spine J. 2008;8(1):8-20. https://doi.org/10.1016/i.spinee.2007.10.0 $\underline{05}$.

2. Simons DG, Travell JG, Simons LS. Travell \& Simons' Myofascial Pain And Dysfunction: Upper Half Of Body. vol 1. Lippincott Williams \& Wilkins; 1999.

3. Kalichman L, Vulfsons S. Dry needling in the management of musculoskeletal pain. J Am Board Fam Med. 2010;23(5):640-646. https://doi.org/10.3122/iabfm.2010.05.09 $\underline{0296 .}$.

4. Cagnie B, Dewitte V, Barbe T, Timmermans F, Delrue N, Meeus M. Physiologic effects of dry needling. Curr Pain Headache Rep. 2013;17(8):348. https://doi.org/10.1007/s1 1916-0130348-5. 
5. Cagnie B, Barbe T, De Ridder E, Van Oosterwijck J, Cools A, Danneels L. The influence of dry needling of the trapezius muscle on muscle blood flow and oxygenation. J Manipulative Physiol Ther. $2012 ; 35(9): 685-691$. https://doi.org/10.1016/i.jmpt.2012.10.00 $\underline{5}$.

6. Gerwin RD. The taut band and other mysteries of the trigger point: an examination of the mechanisms relevant to the development and maintenance of the trigger point. J Muscskelet Pain. 2008;16(12): $115-121$. http://dx.doi.org/10.1080/10582450801 960081.

7. Dommerholt J. Dry needling-peripheral and central considerations. J Man Manip Ther. 2011 ; 19(4):223-227. https://dx.doi.org/10.1179\%2F10669811 1 X13129729552065.

8. Lari AY, Okhovatian F, sadat Naimi S, Baghban AA. The effect of the combination of dry needling and MET on latent trigger point upper trapezius in females. Man Ther. 2016;21:204-209. https://doi.org/10.1016/i.math.2015.08.00 4.

9. Long J, Zhuang X, Tan S, Yan L. Clinical observation of needling of myofascial trigger points and acupoints for myofascial pain syndrome in the lower back. J Guangxi Univ Chin Med. 2012;15:17-9.

10. Chen Z. Study on the super laser therapy on trigger points for low back myofascial pain syndrome. Guangzhou Univ Chin Med. 2014.

11. Hirota S, Itoh K, Katsumi Y. A controlled clinical trial comparing trigger point acupuncture with tender point acupuncture treatments for chronic low back pain-a pilot study on 9 elderly patients. J Japn Acupuncture Moxibustion Soc. 2006;56(1):68-75. http://dx.doi.org/10.3777/iisam.56.68.
12. Itoh K, Katsumi Y. Effect of acupuncture treatment on chronic low back pain with leg pain in aged patients-a controlled trial about short-term effects of trigger point acupuncture. J Japn Acupuncture Moxibustion Soc. $2005 ; 55(4): 530-537$.

13. Itoh K, Katsumi Y, Hirota S, Kitakoji H. Effects of trigger point acupuncture on chronic low back pain in elderly patients-a shamcontrolled randomised trial. Acupunct Med. 2006;24(1):5-12.

https://doi.org/10.1136/aim.24.1.5.

14. Itoh K, Katsumi Y, Kitakoji H. Trigger point acupuncture treatment of chronic low back pain in elderly patients-a blinded RCT. Acupunct Med. 2004;22(4):170-177. https://doi.org/10.1136/aim.22.4.170.

15. Kuang J. A research on acupuncture at trigger points treatment for chronic low back myofascial pain syndrome. Guangzhou Univ Chin Med. 2013.

16. Mahmoudzadeh A, Rezaeian ZS, Karimi A, Dommerholt $J$. The effect of dry needling on the radiating pain in subjects with discogenic low-back pain: a randomized control trial. $J$ Res Med Sci. 2016;21. https://dx.doi.org/10.4103\%2F17351995.192502.

17. Shen C, Ding J. Clinical observation of effectiveness in the treatment of lumbar disc herniation with intramuscular stimulation therapy 30 cases reports. Zhejiang J Tradit Chin Med. 2015;50:676.

18. Yang $X$, Zhou Y. Clinical observation of effectiveness in the treatment of myofascial pain syndrome in the lower back with intramuscular stimulation therapy. Chin J Rural Med Pharm. 2010;17:44-5.

19. Téllez-García $M$, de-la-Llave-Rincón Al, Salom-Moreno J, Palacios-Ceña M, OrtegaSantiago R, Fernández-de-las-Peñas $C$. Neuroscience education in addition to trigger point dry needling for the management of patients with mechanical chronic low back pain: a preliminary clinical trial $J$ Bodyw Mov Volume 4 - Issue 2 - September 2021 
Ther. $2015 ; 19(3): 464-472$.

https://doi.org/10.1016/i.jbmt.2014.11.01

$\underline{2}$.

20. Liu L, Huang Q-M, Liu Q-G, et al. Evidence

for dry needling in the management of myofascial trigger points associated with low back pain: a systematic review and metaanalysis. Arch Phys Med Rehabil.

2018;99(1):144-152. e2.

https://doi.org/10.1016/i.apmr.2017.06.0

08.

21. Gattie E, Cleland JA, Snodgrass S. The effectiveness of trigger point dry needling for musculoskeletal conditions by physical therapists: a systematic review and metaanalysis. J Orthop Sports Phys Ther. 2017;47(3):133-149. https://doi.org/10.2519/iospt.2017.7096.

22. Alaei $P$, Ansari NN, Naghdi S, Fakhari Z, Komesh S, Dommerholt J. Dry Needling for Hamstring Flexibility: A Single-Blind Randomized Controlled Trial. J Sport Rehabil. 2020;1 (aop): 1 -6. https://doi.org/10.1123/isr.2020-0111.

23. Mason JS, Crowell M, Dolbeer J, et al. The effectiveness of dry needling and stretching vs. stretching alone on hamstring flexibility in patients with knee pain: a randomized controlled trial. Int J Sport Phy Ther. 2016;11(5):672. 